\title{
Experimental Study of Residual Tensile Strength of Drilled Composite
}

\author{
Girish D. Pandit*, Kaushal Prasad \\ Finolex Academy of Management and Technology, Ratnagiri, Maharashtra, 415612 Indian. \\ *Corresponding author. Tel.: +917066128592; email: girishpandit92@gmail.com \\ Manuscript submitted January 4, 2017; accepted March 27, 2017. \\ doi: 10.17706/ijmse.2017.5.1.35-46
}

\begin{abstract}
The work presented in this paper mainly focuses on machining of composites. In composite materials, two or more constituents are combined at microscopic level to achieve required properties. The constituents in composites are softer matrix and high strength fibers. The study for manufacturing processes of composites is necessary because mechanical properties are dependent on these processes. The machining process like drilling has effect on mechanical properties of composite materials. Though curing process residual stresses are getting induced in the composite materials during their fabrication, these stresses are not considered in this study. In this paper, the optimization of drilling parameters (Cutting speed, Feed rate, Drill point angle, Chisel edge width) in drilling of CFRP composite specimen is done using Taguchi method. The effect of variation of these parameters on residual tensile strength of specimen and surface roughness of drilled hole is studied. The optimum parameter levels based on signal to noise ratio plots are decided. The percentage contribution of each factor to the response is found out by analysis of variance. Analysis of variance shows that, speed is the factor having major contribution for the residual tensile strength followed by chisel edge width, drill point angle and feed rate. For the surface roughness drill point angle has major contribution followed by speed, feed and chisel edge width.
\end{abstract}

Keywords: Analysis of variance, drilling, residual tensile strength, Taguchi method.

\section{Introduction}

The Composite materials are important, now a days, because these materials have performed role of conventional solid metals in many applications in very efficient manner. The composites, which may contain glass or carbon fibers have got wide use in automobile industry for making leaf springs, seats, body panels etc. Composite materials are the combination of two or more constituent materials which gives the final product to have properties, which are not identical to any of the constituent material. The advantage of composite materials is that, they have higher strength and stiffness than conventional solid materials for the same weight. The low weight of components made of composite materials is due to their low density. Non-isotropic nature of composites makes it possible to tailor their properties according to the design requirements. Due to which fiber orientation can be kept in the direction of major stresses. Aspect ratio is a term defined as ratio of Length to diameter of a fiber. Continuous fibers have longer aspect ratios. For the use of composite parts in various fields such as aircraft, space, automotive, sporting goods, marine etc. they undergo manufacturing processes. At the same time these parts are to be assembled with other body parts. Hence for assembly, drilling of composite parts is necessary. One among those composites is carbon fiber reinforced plastic (CFRP) which has large application areas. The drilling operation causes 
defects to the CFRP components in the form of delamination, micro-cracks, matrix burning, Fiber pull out etc. [1]. The optimum machining parameters are required for minimum defects to the components in drilling operation.

Because of the damage generated during such machining operations there is change in after machining mechanical behavior of the composite product. R. A. Kishore et al. [1] studied drilling parameters to get maximum after drilling tensile strength using the Taguchi method. The optimum levels of the drill point geometry, the cutting speed and the feed rate have been determined. Drilling is the method which accompanies $40 \%$ of all material removal processes. The drilling induced damage could be reduced with the use of special drill bits. C. C. Tsao [2] conducted the drilling experiments with step-core drill to investigate the thrust force. The delamination is related to the thrust force. The parameters taken were diameter ratio, feed rate and spindle speed. Results shows that diameter ratio and feed rate have most significant influence on thrust force. The geometrical parameters of drill have influence on the behavior of drilled composites. The effect of all the forces acting on drill is represented by resisting torque and thrust force. The action at the chisel edge is not truly a cutting action, but it is pushing action into material like a wedge. The optimization of drilling parameters like cutting speed, feed, point angle and chisel edge width in drilling of glass fiber reinforced polymer (GFRP) composites is done by Vinod Kumar Vankanti et al. [3]. The aspects of the mathematical analysis and use of non- traditional methods in machining of composites is reviewed by H. Hocheng et al. [4]. Among the various drill types twist drill causes larger thrust force, but still it is most economical to use twist drills. As drilling induced thrust force increases beyond critical thrust force the delamination occurs. The evaluation of delamination factor in drilling of CFRP composites is done by C. C. Tsao et. al. with the use ultrasonic C-scan technique [5]. The technique of acoustic emission for measurement of residual tensile strength of drilled composite was used by Navid Zarif Karimi et al. [6]. This is most accurate method for determining mechanical properties of composite materials. E. Kilickap [7] investigated the influence of the cutting parameters, such as cutting speed and feed rate, and point angle on delamination produced when drilling a GFRP composite. There is concept of 'Pooling' in analysis of variance, which was referred from the study done by Prabodh B. Horambe et al. [8]. The results of first part of experimentation of the present work, which are to be continued in current paper are given in Girish Pandit et al. [9]. The study of residual tensile strength after drilling in flax natural fiber epoxy composite was done by Abdul Nasir, A. A. et al. [10]. And in this study, they found that feed rate is the most significant parameter to affect the residual tensile strength.

\section{Experimentation}

\subsection{CFRP Specimen and Cutting Tool}

From the gaps observed in previous studies, it is decided to work on CFRP specimen which is bi-directional fabric of carbon fiber and prepared by hand lay up using compression molding process. The fiber orientation was kept at $0^{\circ}$ and $90^{\circ}$. Phenolic resin bonding material was used. The specimen specifications are given in Table 1.

Table 1. CFRP (Woven) Specimen Material Specification

\begin{tabular}{|c|l|c|}
\hline Sr. No. & Specification & Value \\
\hline 1 & Fiber orientation & $0-90$ degrees \\
\hline 2 & Number of layers & 8 \\
\hline 3 & Fiber strength & 79 \\
\hline 4 & Fiber density & $1.6 \mathrm{~g} / \mathrm{cm}^{3}$ \\
\hline 5 & Resin density & $1.15 \mathrm{~g} / \mathrm{cm}^{3}$ at $20^{\circ} \mathrm{C}$ \\
\hline 6 & Fiber Volume fraction & 6 \\
\hline
\end{tabular}


The specimen geometry was taken as per the guidelines of ASTM D3039 standards as shown in Fig. 1. The tools used for drilling process are HSS twist drills of $8 \mathrm{~mm}$ diameter. The parameters and their levels were decided after thorough literature survey and looking at their significance.

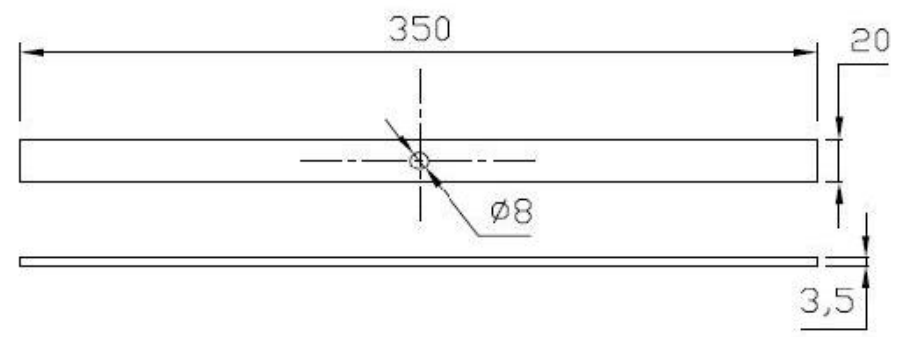

Fig. 1. Specimen geometry (As per ASTM D3039, all dimensions are in mm).

\subsection{Experimental Set Up}

The drilling was done on fully automatic 3-axis vertical milling machine of make BFW and model BMV-40. The power rating of spindle motor is $3.7 \mathrm{KW}$ and spindle speed range of $60-6000 \mathrm{rpm}$. The machine has cutting feed rate range of $1-4000 \mathrm{~mm} / \mathrm{min}$. The geometry of specimen for drilling as per ASTM D3039 is shown in Fig.1. For drilling experiments the four parameters having three levels each were used. The process parameters taken were cutting speed and feed rate. Drill point angle and chisel edge width were the geometrical parameters. The cutting speed was varied from 1500 to $2500 \mathrm{rpm}$ while feed rate values taken were 10,15 and $20 \mathrm{~mm} / \mathrm{min}$. The drilling process on vertical milling machine is shown in Fig. 2.

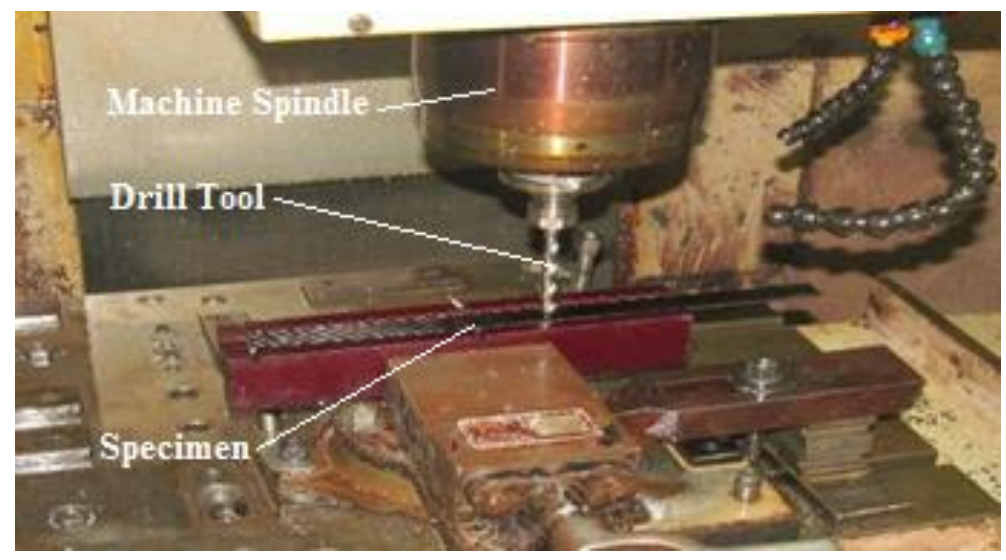

Fig. 2. Drilling process on vertical milling machine

\section{Taguchi Method}

A full factorial design results in large number of experiments. This full factorial design considers all the possible combinations of factors and levels for the experiments. It is not practically possible every time to conduct experiments for all possible combinations. So, in Taguchi method small set from all possible combinations is taken and it is called as partial fraction experiment. Also Taguchi analysis provides special set of general design guidelines for factorial experiments. Taguchi method gives following steps for designing the experiments [1]: (1) establishment of objective function (2) identification of factors and their levels (3) selection of appropriate orthogonal array (4) experimentation (5) analysis of data and determination of optimal levels (6) the confirmation experimentation. 


\subsection{Establishment of Objective Function}

The objective of Taguchi method is to produce high quality product in minimum cost to the manufacturer. The main objective of this study is to determine optimal parameter levels which will give maximum Residual Tensile Strength of the specimen and minimum surface roughness of the drilled hole. The drilling is done in carbon fiber phenol composite specimens.

\subsection{Identification of Factors and Their Levels}

In Taguchi method the factors affecting the quality of process are divided as control factors and noise factors. Control factors are set by manufacturer and can be adjusted. But these factors cannot be directly changed by the customer. The noise factors are due to uncontrollable factors and these causes variation in output. There are three categories of noise factors like Outer noise, Inner Noise and Product noise. Outer noise depends on environment in which batches of products are treated. Inner noise is due to internal factors like deterioration, wear, shrinkage etc. Product noise occurs due to variation among different parts. Control factors are most important for quality of product characteristic [13]. In present study, the parameters taken are cutting speed ( $\mathrm{rpm})$, feed rate $(\mathrm{mm} / \mathrm{min})$, drill point angle (degree) and chisel edge width $(\mathrm{mm})$ with having three levels each. The parameters and their levels are shown Table 2.

Table 2. Factors and Levels for Experiment

\begin{tabular}{|c|c|c|c|c|c|}
\hline & & \multicolumn{4}{|c|}{ Factors } \\
\hline & & $\begin{array}{c}\text { A:Speed } \\
(\mathrm{rpm})\end{array}$ & $\begin{array}{l}\text { B: Feed } \\
(\mathrm{mm} / \mathrm{min} .)\end{array}$ & $\begin{array}{c}\text { C:Drill } \\
\text { point } \\
\text { angle(deg.) }\end{array}$ & $\begin{array}{c}\text { D: Chisel } \\
\text { edge } \\
\text { width }(\mathrm{mm})\end{array}$ \\
\hline \multirow{3}{*}{ 先 } & 1 & 1500 & 10 & 100 & 1 \\
\hline & 2 & 2000 & 15 & 118 & 2 \\
\hline & 3 & 2500 & 20 & 135 & 3 \\
\hline
\end{tabular}

\subsection{Selection of Taguchi Orthogonal Array}

The Taguchi orthogonal array gives minimum number of experiments which could give full information of all the factors that affect the performance [13]. There are many standard orthogonal arrays available. In each array there are specific number of independent design parameters and levels. The L9 orthogonal array is used in this study. Table 3 shows L9 orthogonal array.

Table 3. The L9 Orthogonal Array

\begin{tabular}{|c|c|c|c|c|}
\hline $\begin{array}{c}\text { Experiment } \\
\text { No. }\end{array}$ & $\begin{array}{c}\text { Speed } \\
(\mathrm{rpm})\end{array}$ & $\begin{array}{c}\text { Feed } \\
(\mathrm{mm} / \mathrm{min})\end{array}$ & $\begin{array}{c}\text { Drill point } \\
\text { angle } \\
\text { (degrees) }\end{array}$ & $\begin{array}{c}\text { Chisel edge } \\
\text { width (mm) }\end{array}$ \\
\hline 1 & 1500 & 10 & 100 & 1 \\
\hline 2 & 1500 & 15 & 118 & 2 \\
\hline 3 & 1500 & 20 & 135 & 3 \\
\hline 4 & 2000 & 10 & 118 & 3 \\
\hline 5 & 2000 & 15 & 135 & 1 \\
\hline 6 & 2000 & 20 & 100 & 2 \\
\hline 7 & 2500 & 10 & 135 & 2 \\
\hline 8 & 2500 & 15 & 100 & 3 \\
\hline 9 & 2500 & 20 & 118 & 1 \\
\hline
\end{tabular}




\subsection{Signal to Noise Ratio}

The SN ratio or signal to noise ratio is measure of variation present. The SN ratio gives single value consolidating several repetitions, which gives variation present. From plots of SN ratios one can find the factor levels at which there is minimum effect of noise on response [13]. The different SN ratios depending upon type of quality characteristic are: (1) Lower is better (2) Nominal is best (3) Higher is better. In present work, for the first part, for which response is residual tensile strength, the objective is to maximize residual tensile strength. Hence, for analysis higher is better quality characteristic is used. It is given as,

$$
\frac{S}{N}=-10 \log \left(\frac{1}{r} \sum_{i=1}^{r} \frac{1}{y_{i}^{2}}\right)
$$

Also for the case of surface roughness lower is better quality characteristic is used. And it is given as,

$$
\frac{S}{N}=-10 \log \left(\frac{1}{r} \sum_{i=1}^{r} y_{i}^{2}\right)
$$

where, $r=$ number of repetitions and $\mathrm{y}_{\mathrm{i}}=$ reading at $\mathrm{ith}^{\text {th }}$ experiment.

\section{Measurement}

The residual tensile strength of drilled specimen was measured by Universal Testing Machine. The UTM used was of 40 Tonnes maximum capacity. The width and thickness of each specimen were measured before Tension test at three locations. The measurement of cross-sectional dimensions of the specimen was carried out by outside micrometer having least count of $0.01 \mathrm{~mm}$. The surface roughness of drilled hole is measured by surface tester of make Mitutoyo and SJ-400 model. Among Ra, $\mathrm{Rz}$ and $\mathrm{Rq}$ values obtained from surface tester, the Ra value is considered for deciding hole quality. The surface roughness results for experiment number 2, 3, 5 and 9 were given in [9]. Along with those results further part is continued in this paper. Ra values for all specimens were measured. The experimental results for tensile strength and surface roughness of the L9 orthogonal array experiment are shown in Table 4.
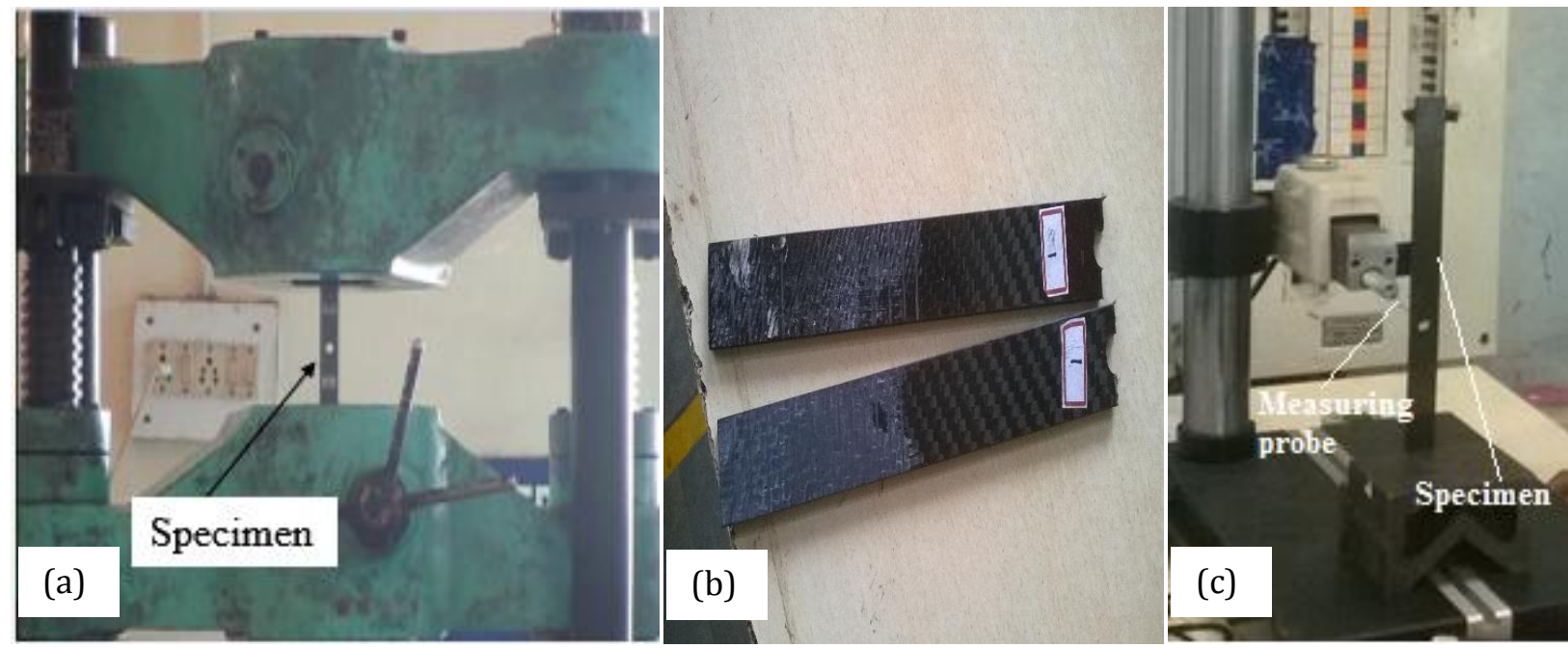

Fig. 3. Experimental testing: (a) Tensile test; (b) Specimen after tensile test; (c) Surface roughness test. 
Table 4. Experimental results of L9 Orthogonal Array

\begin{tabular}{|c|c|c|c|}
\hline $\begin{array}{c}\text { Experiment } \\
\text { No. }\end{array}$ & $\begin{array}{c}\text { Tensile Load } \\
(\mathrm{KN})\end{array}$ & $\begin{array}{c}\text { Tensile Strength } \\
(\mathrm{MPa})\end{array}$ & $\begin{array}{c}\text { Surface Roughness } \\
(\mu \mathrm{m})\end{array}$ \\
\hline 1 & 12.18 & 302.415 & 0.81 \\
\hline 2 & 10.68 & 266.946 & 1.43 \\
\hline 3 & 10.46 & 247.975 & 1.08 \\
\hline 4 & 14.98 & 389.497 & 2.78 \\
\hline 5 & 14.66 & 353.122 & 1.19 \\
\hline 6 & 10.82 & 280.477 & 2.34 \\
\hline 7 & 13.26 & 309.145 & 0.78 \\
\hline 8 & 12.98 & 320.545 & 1.73 \\
\hline 9 & 14.02 & 354.744 & 2.68 \\
\hline
\end{tabular}

\section{Result Analysis}

\subsection{Analysis of Residual Tensile Strength}

The optimum parameters based on main effects plot for $\mathrm{SN}$ ratios for residual tensile strength are taken. The main effects plot graphically represents the effect of factors on the response which helps to compare the effect of each level of the control factor on the response under study [8]. The main effects plot gives effect of chosen factors on output i.e. response from which the effect of each level of control factor on response is compared.

The main effect plots for means and SN ratios as obtained from Minitab 17 software are given in Fig.4 and Fig.5. The reference line drawn is showing the average mean for overall response. From the main effect plots it is clear that the residual tensile strength will be maximum at level 2 for speed (2000 rpm), level 1 for feed rate $(10 \mathrm{~mm} / \mathrm{min})$, level 2 of drill point angle (118degree) and level 1 of chisel edge width $(1 \mathrm{~mm})$. The larger is better quality characteristic has been set for SN ratio plot. One can verify the optimum parameter levels by the main effects plot for means.

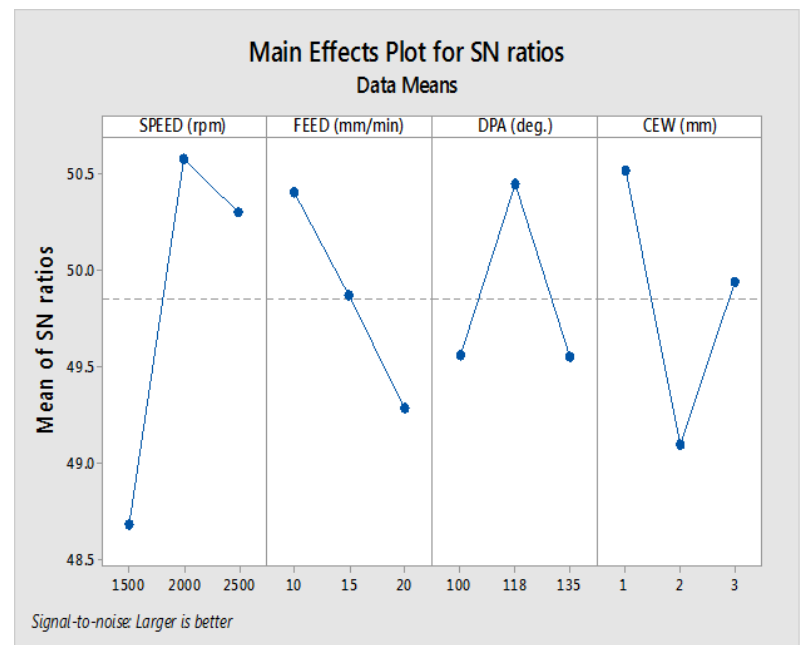

Fig.4 Main effects plot for SN ratio for residual tensile strength.

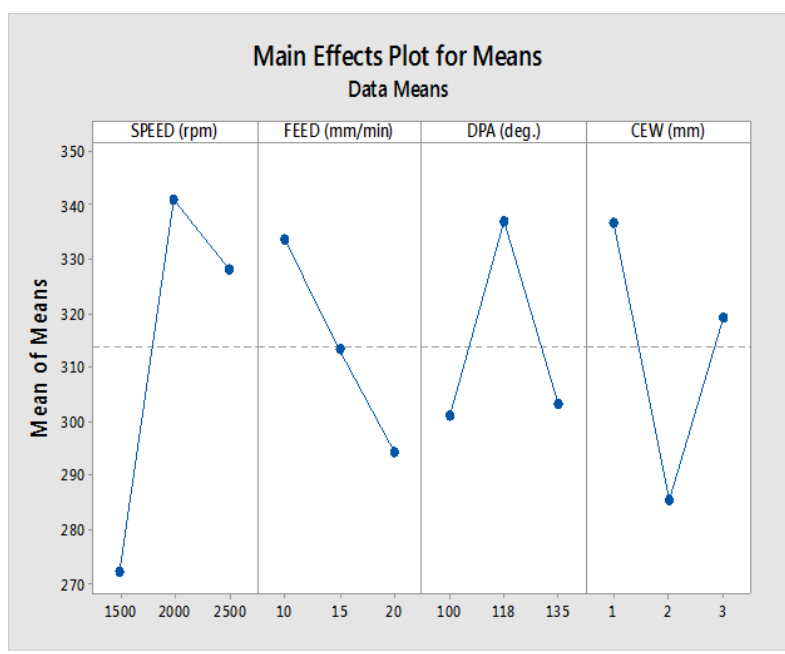

Fig.5 Main effects plot for means for residual tensile strength. 
The percent contribution of factors is obtained from Analysis of variance (ANOVA) for obtained results as shown in Table 4. Now in order to find out significant factors involved in the analysis determination of their percent contribution $\mathrm{F}$ ratio is needed. Applying analysis of variance (ANOVA) it can be done. The percent contribution is a function of sum of squares of each control factor. In L9 array which is chosen for analysis, total degrees of freedom available are 9-1=8 [13]. Three levels of each factors are considered, so all four factors are assigned with 2 degrees of freedom each.

Table 4. ANOVA Table Residual Tensile Strength

\begin{tabular}{|c|l|l|l|l|l|l|}
\hline Sr. No. & Factor & DOF & SS & MSS & F-Ratio & \% Contribution \\
\hline 1 & Speed (rpm) & 2 & 7973 & 3986 & & 47.492 \\
\hline 2 & Feed(mm/min) & 2 & 2316 & 1158 & & 13.796 \\
\hline 3 & DPA (deg.) & 2 & 2427 & 1214 & & 14.457 \\
\hline 4 & CEW (mm) & 2 & 4072 & 2036 & & 24.255 \\
\hline 5 & Error & 0 & 0 & - & & - \\
\hline 6 & Total & 8 & 16788 & & & \\
\hline
\end{tabular}

As degrees of freedom was assigned to the error is coming as zero, it was not possible to calculate the mean sum of square for error and hence the F ratio. The concept of pooling was used [13], in which one of the controlling parameter having least percentage contribution can be 'pooled' to the error that means its contribution is considered as an error and added into it. This allows to assign 2 degrees of freedom to the error from which mean sum of square is calculated and ultimately $\mathrm{F}$ ratio can be obtained. The modified ANOVA table after incorporating these conditions is shown in the Table 5. From Table 5 for the tensile strength, it is clear that percent contribution of feed is minimum so it is pooled to error. The percent contribution of all the factors along with error is shown graphically in Fig. 6.

Table 5. Modified ANOVA Table for Residual Tensile Strength

\begin{tabular}{|c|c|c|c|c|c|c|}
\hline Sr. No. & Factor & SS & DOF & MSS & F ratio & \%Contribution \\
\hline 1 & Speed(rpm) & 7973 & 2 & 3986 & 3.44 & 47.492 \\
\hline 2 & Feed(mm/min) & \multicolumn{5}{|c|}{ Pooled } \\
\hline 3 & DPA (deg.) & 2427 & 2 & 1214 & 1.04 & 14.457 \\
\hline 4 & CEW (mm) & 4072 & 2 & 2036 & 1.75 & 24.255 \\
\hline 5 & Error & 2316 & 2 & 1158 & - & 13.796 \\
\hline 6 & Total & 16788 & 8 & & & \\
\hline
\end{tabular}

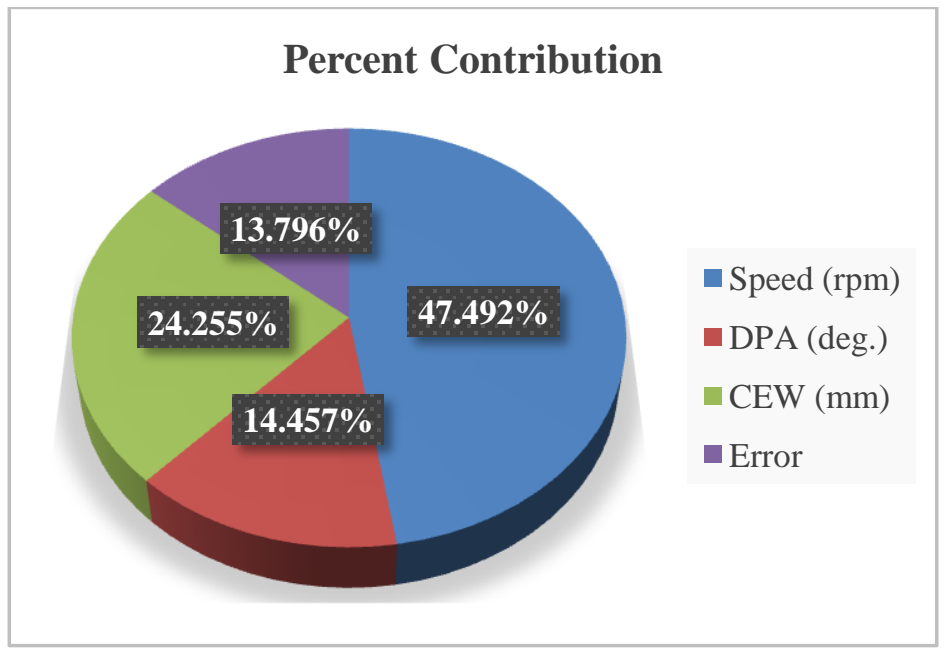

Fig. 6 Percent contribution of factors for Residual Tensile Strength. 


\subsection{Analysis of Surface Roughness}

The optimum parameters based on main effects plot for SN ratios for surface roughness are decided. The graphs for main effects plot for SN ratios and mean are shown in Fig. 7 and Fig. 8 for surface roughness. The main effects plot graphically represents the effect of factors on the response. The reference line drawn is showing the average mean for overall response. From the main effect plots it is clear that the surface roughness will be minimum at level 1 for speed (1500rpm), level 1 for feed rate $(10 \mathrm{~mm} / \mathrm{min})$, level 3 of drill point angle (135 degree) and level 1 of chisel edge width $(1 \mathrm{~mm})$.

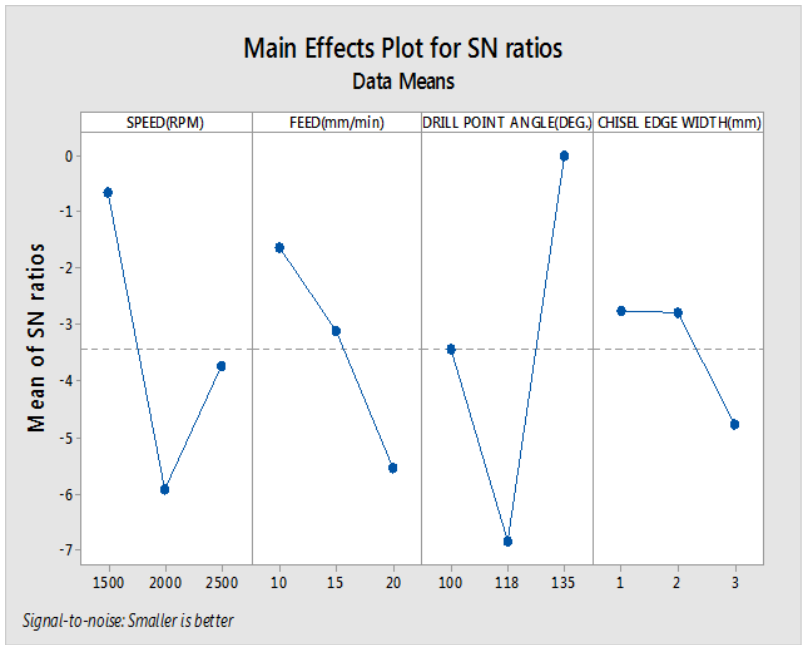

Fig. 7 Main effects plot for means for SN ratios for surface roughness.

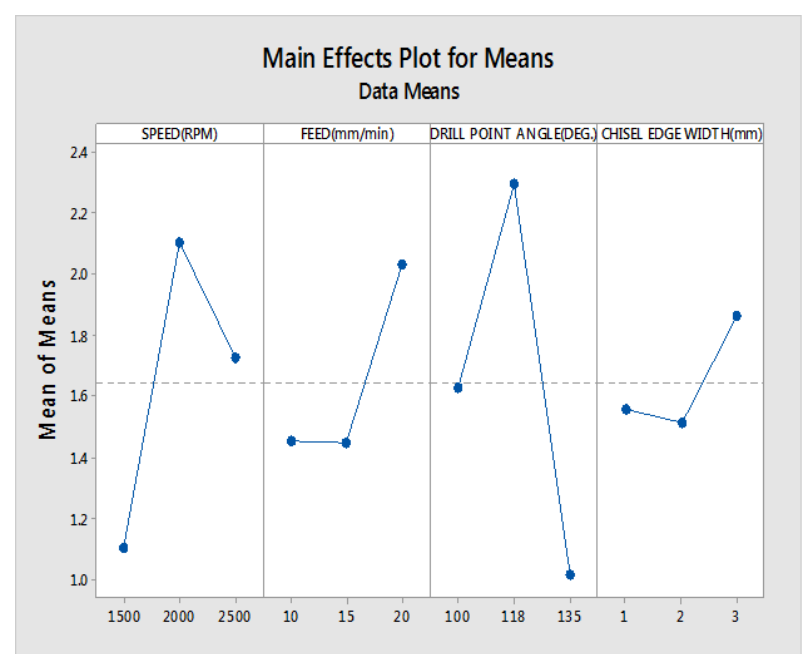

Fig. 8 Main effects plot for means for surface roughness.

For determining percent contribution of each factor on response analysis of variance need to be done. Table 6 and Table 7 gives ANOVA tables for surface roughness. Similar analysis is done for surface roughness as that of residual tensile strength. In which chisel edge width is 'pooled' to error due to inconvenience caused in calculating F-ratio. As can be seen from the Table 7 drill point angle is most contributing factor followed by speed and feed.

Table 6. ANOVA Table for Surface Roughness

\begin{tabular}{|c|c|c|c|c|c|c|}
\hline Sr. No. & Factor & SS & DOF & MSS & F ratio & \% Contribution \\
\hline 1 & Speed (rpm) & 1.521 & 2 & 0.761 & & 31.24 \\
\hline 2 & Feed (mm/min) & 0.6729 & 2 & 0.336 & & 13.82 \\
\hline 3 & DPA ( ${ }^{\circ}$ & 2.459 & 2 & 1.230 & & 50.51 \\
\hline 4 & CEW $(\mathrm{mm})$ & 0.2141 & 2 & 0.107 & & 4.40 \\
\hline 5 & Error & 0 & 0 & - & & - \\
\hline 6 & Total & 4.868 & 8 & & & 100 \\
\hline
\end{tabular}

Table 7. Modified ANOVA Table for Surface Roughness

\begin{tabular}{|c|c|c|c|c|c|c|}
\hline Sr. No. & Factor & SS & DOF & MSS & F & \% Contribution \\
\hline 1 & Speed (rpm) & 1.521 & 2 & 0.761 & 7.11 & 31.24 \\
\hline 2 & Feed(mm/min) & 0.6729 & 2 & 0.336 & 3.14 & 13.82 \\
\hline 3 & DPA (deg.) & 2.459 & 2 & 1.231 & 11.50 & 50.51 \\
\hline 4 & CEW (mm) & \multicolumn{5}{|c|}{ Pooled } \\
\hline 5 & Error & 0.2141 & 2 & 0.107 & - & 4.40 \\
\hline 6 & Total & 4.868 & 8 & & & 100 \\
\hline
\end{tabular}




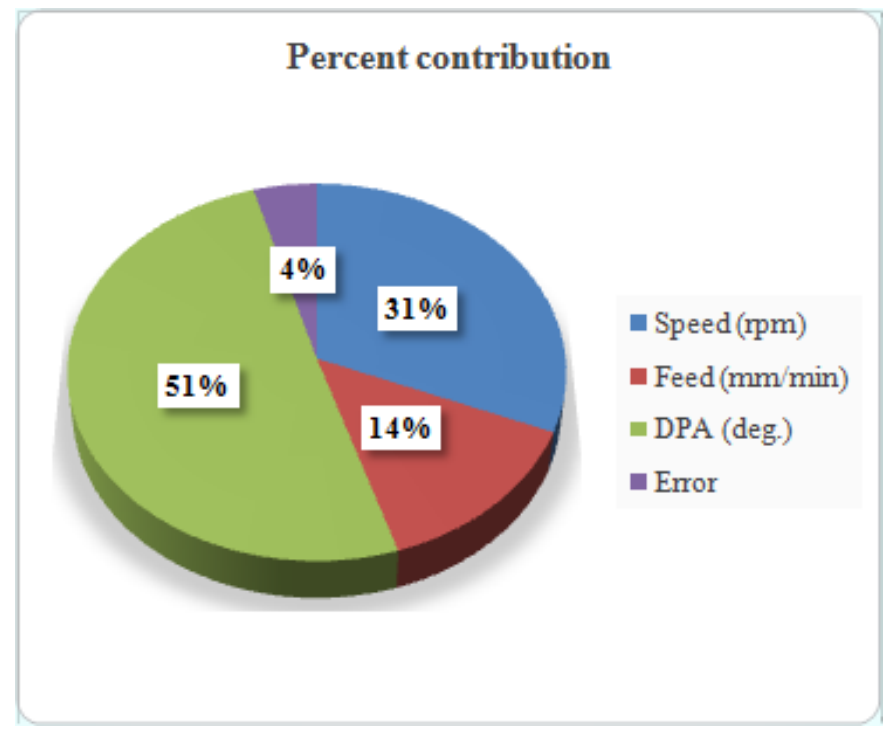

Fig. 9. Percent contribution of factors for Surface roughness.

\subsection{Estimated Mean of All Responses}

Once the optimal combination of process parameters and their levels was obtained, the final step was to verify the estimated result against experimental value. It may be noted that if the optimal combination of parameters and their levels coincidently match with one of the experiments in the Orthogonal Array, then no confirmation test is required. Estimated value of all the responses at optimum condition was calculated by adding the average performance to the contribution of each parameter at the optimum level using the following equations (3) and (4) [13]. Table 8 and Table 9 shows estimated results for residual tensile strength and surface roughness respectively.

Estimated Tensile strength at optimum condition is computed by

$$
\hat{\mu}=\overline{\mathrm{A} 2}+\overline{\mathrm{C} 2}+\overline{\mathrm{D} 1}-2 \overline{\mathrm{T}}
$$

Estimated Surface roughness at optimum condition is computed by

$$
\hat{\mu}=\overline{\mathrm{A} 1}+\overline{\mathrm{B} 1}+\overline{\mathrm{C} 3}-2 \overline{\mathrm{T}}
$$

Table 8. Estimated Residual Tensile Strength at Optimum Condition

\begin{tabular}{|c|c|c|c|c|}
\hline $\begin{array}{c}\text { Grand } \\
\text { Average }\end{array}$ & Speed & $\begin{array}{c}\text { Drill Point } \\
\text { Angle }\end{array}$ & $\begin{array}{c}\text { Chisel Edge } \\
\text { Width }\end{array}$ & $\begin{array}{c}\text { Estimated } \\
\text { strength }\end{array}$ \\
\hline$\overline{\mathrm{T}}$ & $\overline{\mathrm{A} 2}$ & $\overline{\mathrm{C} 2}$ & $\overline{\mathrm{D} 1}$ & \\
\hline 313.874 & 341.043 & 337.062 & 336.760 & 387.117 \\
\hline
\end{tabular}

Table 9. Estimated Surface Roughness at Optimum Condition

\begin{tabular}{|c|c|c|c|c|}
\hline $\begin{array}{c}\text { Grand } \\
\text { Average }\end{array}$ & Speed & Feed & $\begin{array}{c}\text { Drill Point } \\
\text { Angle }\end{array}$ & $\begin{array}{c}\text { Estimated } \\
\text { roughness }\end{array}$ \\
\hline$\overline{\mathrm{T}}$ & $\overline{\mathrm{A} 1}$ & $\overline{\mathrm{B} 2}$ & $\overline{\mathrm{C} 3}$ & \\
\hline 1.647 & 1.107 & 1.457 & 1.017 & 0.287 \\
\hline
\end{tabular}


The estimated results by the formulae given by equations (3) and (4) earlier are only a point estimate based on the averages of the results obtained from the experiments. While performing the confirmation experiment it is better to have a range of value than having an exact value of predicted results within which the observed values should fall at some percentage of confidence. This range is called as confidence interval (C.I.) [13]. It has a maximum and minimum value between which the observed value should fall. The statistical approach to calculate confidence interval is by using formula in equation (5),

$$
\text { C. I. }= \pm \sqrt{\left(\mathrm{F}_{\left(1, \mathrm{n}_{2}\right)} \times \mathrm{V}_{\mathrm{e}}\right) / \mathrm{N}_{\mathrm{e}}}
$$

where $\mathrm{F}(1, \mathrm{n} 2)$ is the $\mathrm{F}$ value from $\mathrm{F}$ table at a required confidence level at DOF 1 and error DOF $\mathrm{n} 2, \mathrm{Ne}=$ Effective number of replications, Ve is the error variance which is mean sum of squares for error.

Using these equations confidence interval for responses is calculated which is shown in Table 8. The $\mathrm{F}$ value is taken for $95 \%$ of confidence.

Table 8. Comparison between Experimental Results and Predicted Results

\begin{tabular}{|c|c|c|c|c|c|}
\hline \multirow{2}{*}{$\begin{array}{c}\text { Sr. } \\
\text { No. }\end{array}$} & Response & \multirow{2}{*}{$\begin{array}{c}\text { Predicted } \\
\text { Results }\end{array}$} & \multicolumn{2}{|c|}{$\begin{array}{c}\text { Confidence } \\
\text { Interval (C. I.) limits }\end{array}$} & \multirow{2}{*}{$\begin{array}{c}\text { Observed } \\
\text { Results }\end{array}$} \\
\cline { 4 - 5 } 1 & $\begin{array}{c}\text { Tensile Strength } \\
(\mathrm{MPa})\end{array}$ & 387.12 & 158.22 & 616.02 & 396.62 \\
\hline 2 & $\begin{array}{c}\text { Surface Roughness } \\
(\mu \mathrm{m})\end{array}$ & 0.287 & -1.91 & 2.48 & 1.4 \\
\hline
\end{tabular}

\subsection{Confirmation Experiments}

The confirmation experiments for optimum levels of parameters were performed. The results of confirmation experiment for Residual tensile strength and Surface roughness were seem to be with in the limits of confidence interval. These results are given in Table 8 as observed results. Hence, in this experimentation work the significant factors and their appropriate levels were properly chosen to obtain desired results.

\subsection{Regression Analysis}

On the basis of available data of experiments, the empirical relation is developed between the response and parameters used in experimentation. This empirical relation which defines response in terms of parameters is called as regression model. In regression model response is dependent variable whereas parameters are independent variables. When number of parameters are two or more, it is called multiple regression. Regression models are used to predict data from unplanned experiments [12], [13]. The regression equation can be obtained by using Minitab software. The regression model for tensile strength and surface roughness are as given in equations (6) and equation (7),

$$
\begin{gathered}
\text { Tensile Strength }=269+0.0557 \text { Speed }-3.93 \text { Feed }+0.08 \text { DPA }-8.7 \text { CEW } \\
\text { Surface roughness }=1.22+0.000623 \text { Speed }+0.0577 \text { Feed }-0.0169 \mathrm{DPA}+0.152 \mathrm{CEW}
\end{gathered}
$$

\section{Conclusion}

The tests for L9 orthogonal array for two types of responses, named as Residual Tensile strength and 
Surface Roughness were taken for which results are as shown in Table 4. For analysis of experimental results quality characteristic used for Residual Tensile strength was Larger is better, while that used for Surface Roughness was Smaller is better. The maximum Residual Tensile Strength was observed at Speed $2000 \mathrm{rpm}$, Feed rate of $1 \mathrm{~mm} / \mathrm{min}$., and Drill point angle of 118 degrees and Chisel Edge width of $1 \mathrm{~mm}$. From Anova Table 5. It is clear that, among chosen factors Speed has major contribution to the Residual Tensile strength equal to 47.492 percent followed by Chisel edge with and Drill point angle having contribution of 24.255 percent and 14.457 percent respectively. The factor feed rate is having least contribution of 13.796 to the Residual tensile strength and is considered as error.

As speed has major contribution to the strength we can say that as speed increases the fibers are not getting time to get attached with cutting lips, so there would be less fiber pull out. Also at higher speed the fiber burning is there, so speed cannot be increased above certain maximum value.

The arithmetic average roughness ( $\mathrm{Ra}$ ) value is taken in to consideration for hole quality. For Surface roughness, the minimum response value is observed at Speed $1500 \mathrm{rpm}$, Feed rate $10 \mathrm{~mm} / \mathrm{min}$., Drill point angle 135 degree and chisel edge width of $1 \mathrm{~mm}$. From Anova Table 7, it is clear that, among chosen factors Drill point angle has major contribution to the Surface roughness equal to 50.51 percent followed by Speed and Feed rate having contribution of 31.24 percent and 13.82 percent respectively. The chisel edge width has least contribution to the surface roughness which is equal to 4.40 percent. So, it is considered as error for Analysis of variance.

Optimum value of drill point angle is required, having major contribution to the surface roughness, for minimum defects, because increase in DPA value will lead to chisel effect and decrease of DPA value causes more cutting lip area in contact with material causing more heat generation and matrix burning.

\section{References}

[1] Kishore, R. A., Tiwari, R., Dvivedi, A., \& Singh, I. (2009). Taguchi analysis of the residual tensile strength after drilling in glass fiber reinforced epoxy composites. Materials and Design, 30(6), 2186-2190.

[2] Tsao, C. C. (2008). Experimental study of drilling composite materials with step-core drill. Materials and Design, 29(9), 1740-1744.

[3] Vankanti, V. K., \& Ganta, V. (2014). Optimization of process parameters in drilling of GFRP composite using Taguchi method. J. Mater. Res. Technol., 3(1), 35-41.

[4] Hocheng, H., \& Tsao, C. C. (2005). The path towards delamination-free drilling of composite materials. Journal of Materials Processing Technology, 167(2-3), 251-264.

[5] Tsao, C. C., \& Hocheng, H. (2004). Taguchi analysis of delamination associated with various drill bits in drilling of composite material. International Journal of Machine Tools \& Manufacture, 44(10), 1085-1090.

[6] Karimi, N. Z., Heidary, H., \& Ahmadi, M. (2012). Residual tensile strength monitoring of drilled composite materials by acoustic emission. Materials and Design, 40, 229-236.

[7] Kilickap, E. (2010). Optimization of cutting parameters on delamination based on Taguchi method during drilling of GFRP composite. Expert Systems with Applications, 37(8), 6116-6122.

[8] Horambe, P. B., Prasad, K., \& Mestry, S. S. (2016). Experimental parametric study of scarf adhesive joint under static tensile load. International Journal of Materials Science and Engineering, 4(2), 69-79.

[9] Pandit, G. D., \& Prasad, D. K. (2016). Optimization of drilling parameters for hole quality of composite material. In proceedings of National Conference on Recent Advances in Science and Technology (pp. 39-41).

[10] Nasir, A. A. A., Azmi, A. I., \& Khalil, A. N. M. (2015). Parametric study on the residual tensile strength of flax natural fibre composites after drilling operation. In Procedia Manufacturing, 2nd International 
Materials, Industrial, and Manufacturing Engineering Conference (97-101). Bali, Indonesia: Elsevier.

[11] Montgomery, D. C. (2013). Design and Analysis of Experiments. Chichester: John Wiley.

[12] Spiegel, M. R., \& Stephens, L. J. (1972). Theory and Problems of Statistics. New York: McGraw-Hill Publication.

[13] Ross, P. J. (1988). Taguchi Technique for Quality Engineering. New York: McGraw-Hill Publication.

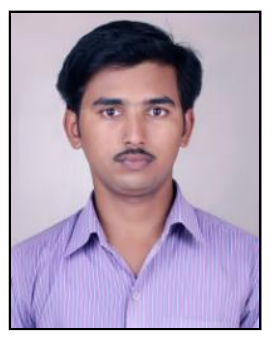

Mr. Girish D. Pandit was born at Satara, Maharashtra, India on $13^{\text {th }}$ august 1992. He has graduated as B.E. in Automobile Engineering at Rajarambapu Institute of Technology (Shivaji University), Sangli, Maharashtra, India in 2014. He has completed his post-graduation as M.E. in Mechanical Engineering (Machine Design) at Finolex Academy of Management and Technology (University of Mumbai ), Ratnagiri, Maharashtra, India in 2017. Machine design and Composite Materials are the major field of study for the Author. He has worked at Finolex Academy of Management and Technology, Ratnagiri, Maharashtra, India as lecturer in Mechanical Engineering Department from 13th Oct. 2014 to 7th Nov. 2016. Currently he is working in mechanical industry as a design engineer at Pune, Maharashtra, India, since 2017. Engineering drawing, computer aided engineering and computer aided drawing are the different topics of his current interest. 